\title{
Height and social class in middle-aged British men
}

\author{
MARY WALKER, A G SHAPER, AND GOYA WANNAMETHEE \\ From the Department of Clinical Epidemiology and General Practice, Royal Free Hospital School of Medicine, \\ London NW3 $2 P F$
}

SUMMARY A study of 7735 middle-aged British men drawn from general practices in twenty-four towns shows that there has been a progressive increase in mean height in the men who were born between 1919 and 1939. This is true for both manual and non-manual classes, but the mean heights of the two groups are significantly different and remain widely separated over this period of time. Manual workers lag twenty years behind non-manual workers in their attained height. Data from other studies indicate that this social class difference in adult height is still present in those born up to 1960. The variation in mean height between the twenty-four towns is less marked than the variation in mean height between the social classes. After social class and age have been taken into account, a "town effect" on height is still present. If height is accepted as an indicator of socio-economic circumstances in childhood, then there is a difference in adult height between social class groups in Great Britain which does not appear to be diminishing.

The adult height of a population is recognized to reflect both genetic factors and the environmental circumstances experienced during the years of growth. The environmental factors identified as associated with growth include family size and birth order, age and smoking status of the mother, birthweight and gestation period, childhood nutrition and diseases in infancy. ${ }^{1-3}$ However, the literature is surprisingly sparse in providing causal evidence for any of these relationships. Demographic measures which represent some of the environmental factors identify time (year of birth/age), place (town of birth and/or residence), and personal factors (social class/economic status) as contributing to the height of a subject. ${ }^{4}$ As these measures are interrelated they require careful analysis in order to assess their proportionate contribution to the determination of height. This paper provides some descriptive data on height in relation to year of birth, social class, and town of residence in a large cohort of middle-aged British men.

\section{Subjects and methods}

The British Regional Heart Study (BRHS) examined 7735 men aged 40-59 selected randomly from one general practice in each of 24 towns in England, Wales and Scotland between 1978 and $1980 .^{5}$ The general practice selected in each town had a social class composition representative of the men in that town. About $\mathbf{4 2 0}$ men were randomly sampled from four stratified age bands of the age-sex register of each practice, and on average a $78 \%$ response rate was achieved, providing approximately 320 subjects from each town. A team of three nurses administered a questionnaire and carried out the physical examinations, rotating through the procedures so that each nurse made a similar number of measurements of each kind in each town.

Height was measured in stockinged feet to the next succeeding $1 \mathrm{~mm}$ on a Harpenden portable stadiometer. The extended neck technique was used to ensure that maximum height was measured. ${ }^{6}$ The subject was asked to stand on the levelled platform, against a vertical scale, with feet together and head in a perpendicular plane. A light-weight cursor with a digital readout was brought to rest on the subject's head and his lower jaw was supported by the nurse. He was asked to breathe in and then out and the digital meter reading was recorded on expiration with the head still supported on the extended neck by the nurse.

Information collected on the administered questionnaire included date and town of birth and longest-held occupation. The latter was coded to one of the Registrar General's six social classes, using the 1970 OPCS manual for occupational classification. Height was not available for two amputees and social class coding could not be carried out on 15 subjects.

Unpublished data on height, measured at 36 years of age in 1637 males as part of the MRC National Survey of Health and Development (1946 birth 


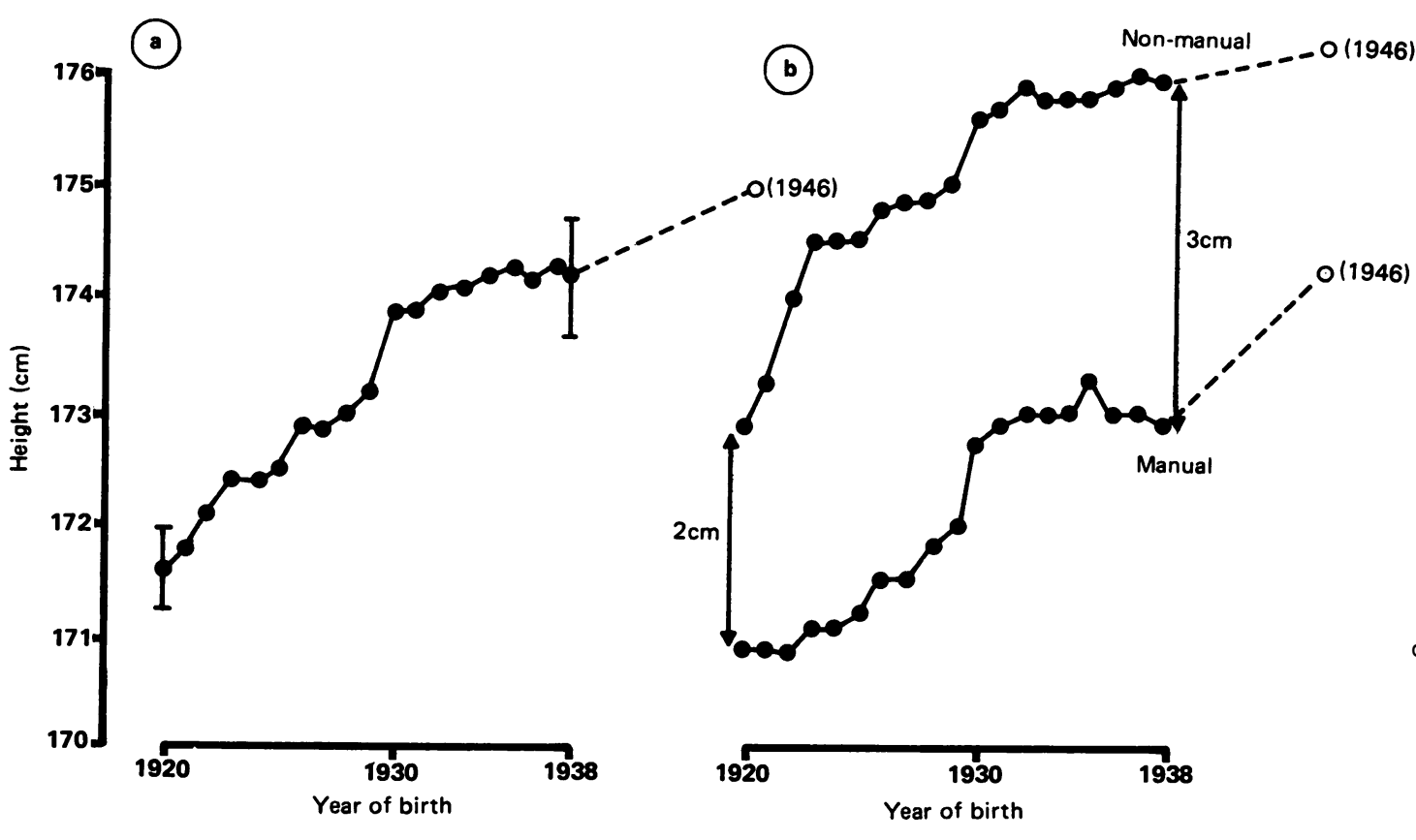

Fig 1 Mean height by year of birth (three year running mean). (a) All men $(n=7487)$. (b) Non-manual and manual workers: $\stackrel{\mathbb{Q}}{\mathrm{Q}} \overrightarrow{\mathrm{D}}$ $\mathrm{O}=1946$ MRC Birth cohort $(n=1637)$

cohort), have been made available to us. These data extend the information on time trends beyond the years available from the British Regional Heart Study. Details of the follow-up sample, the statistical weighting procedure applied and methods used to obtain the heights of this cohort have been published ${ }^{7}$ and are suitable for comparison with the BRHS.

\section{Results}

The distribution of height in the British Regional Heart Study was normal, with a mean of $173.2 \mathrm{~cm}$ $\left(5^{\prime} 8^{\prime \prime}\right)$ and standard deviation $\pm 6.6 \mathrm{~cm}\left(2 \cdot 6^{\prime \prime}\right)$.

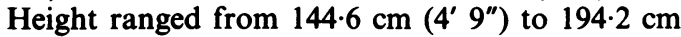
$\left(6^{\prime} 4^{\prime \prime}\right)$. Among the factors affecting this distribution are year of birth, social class and town of residence.

\section{YEAR OF BIR TH}

Age stratified sampling ensured that a similar number of subjects $(350-400)$ were born in each year between 1919 and 1939. Using a three-year running mean the average height increased over this period from a mean height of $171.6 \mathrm{~cm}\left(5^{\prime} 7^{\prime \prime}\right)$ in 1920 to $174.2 \mathrm{~cm}\left(5^{\prime} 8^{\prime \prime}\right)$ in 1938 (figure 1a). The $95 \%$ confidence intervals around these estimates indicate a statistically significant increase in height over the time period studied. The additional point estimate for the height of males in the
1946 birth cohort, weighted for social clas stratification, is $175.0 \mathrm{~cm} \pm 6.5 \mathrm{~cm}$, indicating further increase in growth with time.

SOCIAL CLASS

Longest held occupation is possibly the best available measure of social class in middle-aged men, as it allows for classification of men who are not currently working and for changes in occupation consequent upon ill-health or other causes. This method was used to classify the men into one of the Registrar General's six social classes. The mean height of the social classes ranged from $176.2 \mathrm{~cm}\left(5^{\prime} 9^{\prime \prime}\right)$ in professionals (SC I) to $170.6 \mathrm{~cm}\left(5^{\prime} 7^{\prime \prime}\right)$ in the unskilled manual workers (SC V). The difference in mean height between each of the social classes was statistically significant, except between groups IV and V (figure 2).

SOCIAL CLASS AND YEAR OF BIRTH

When the men are divided into manual and nonmanual groups the mean height increases by year of birth for both groups, from $172.9 \mathrm{~cm}\left(5^{\prime} 8^{\prime \prime}\right)$ to 175.9 $\mathrm{cm}\left(5^{\prime} 9^{\prime \prime}\right)$ in non-manual workers, and from $170.9 \mathrm{~cm}$ $\left(5^{\prime} 7^{\prime \prime}\right)$ to $172.9 \mathrm{~cm}\left(5^{\prime} 8^{\prime \prime}\right)$ in manual workers (figure 1b). The average height of manual workers born in 1938 is the same as that of non-manual workers born in 1920. Manual workers appear to have a twenty-year 


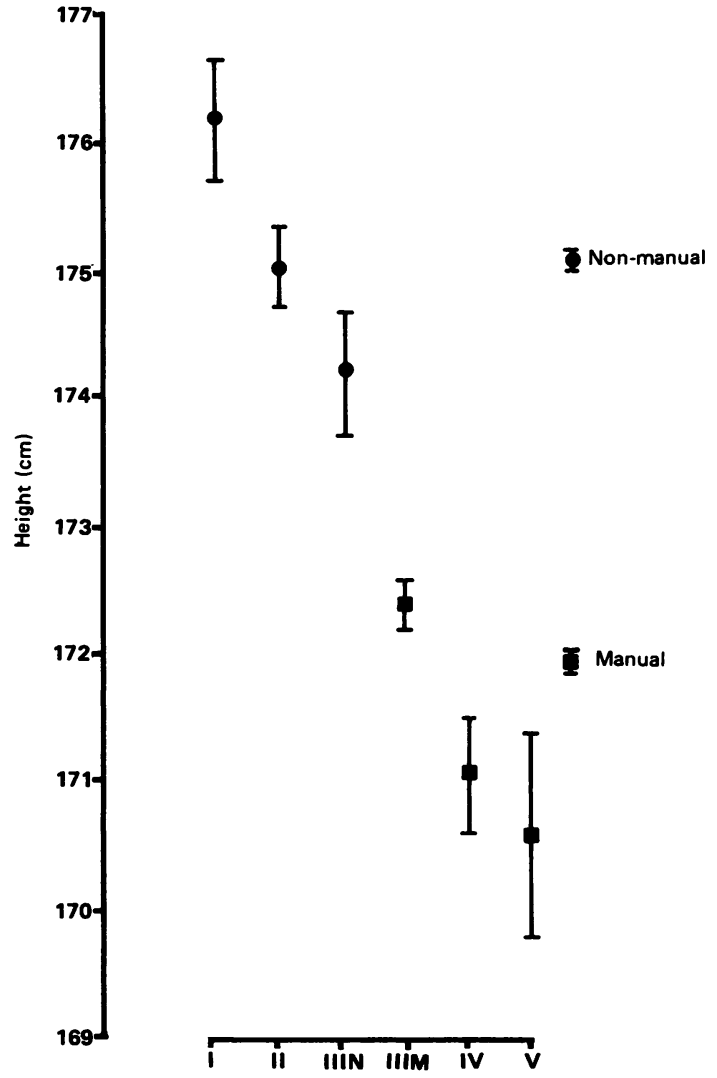

Fig 2 Mean height (with 95\% confidence intervals) by social class.

time lag in their growth pattern relative to non-manual workers. Indeed, the difference in mean height between the groups has increased from $2 \mathrm{~cm}$ to $3 \mathrm{~cm}$ over this 20-year period, but the slopes of the regression lines $(0.17 \mathrm{~cm} /$ year and $0.14 \mathrm{~cm} /$ year, figure 1b) are not significantly different. The first 11 birthyears (1920-30) indicate a period of rapid increase in height for both social groups, after which (1931-38) very little increase in height is recorded in either group. Data from the 1946 birth cohort show that the non-manual workers continued to increase in height over time to $176.3 \mathrm{~cm} \pm 6.4 \mathrm{~cm}$, but that the manual workers had experienced an even larger increase to $174.2 \mathrm{~cm} \pm 6 \cdot 1 \mathrm{~cm}$. However, these data exclude the 105 men who were unemployed at age 36 years and who were significantly shorter than the employed men, and 20 others who could not be classified by social class; together they had a mean height of $172.4 \mathrm{~cm} \pm$ $7.9 \mathrm{~cm}$. If these 125 men had been included in the analysis, the mean heights of both employed groups would be slightly reduced, possibly to a greater extent in the manual than the non-manual workers.
TOWN OF RESIDENCE

Mean height varied between towns, from $170.9 \mathrm{~cm}$ $\left(5^{\prime} 7^{\prime \prime}\right)$ in Merthyr Tydfil to $175.8 \mathrm{~cm}\left(5^{\prime} 9^{\prime \prime}\right)$ in Guildford, a difference of $4.9 \mathrm{~cm}\left(1.9^{\prime \prime}\right)$. Each town is comprised of a varying proportion of the six social classes and has a different mean age due to varying age-related response rates. Adjustment in town mean height was made for both age and social class using analysis of covariance, following which there was still a significant variation between town mean heights (p < 0.01). Furthermore, a strong correlation $(r=0.44, p=0.03)$ is found between the mean heights in manual workers and non-manual workers for each of the 24 towns. This again suggests a "town effect" independent of social class.

The lowest $20 \%$ of the height distribution for all men $(<167.9 \mathrm{~cm})$ was selected as the criterion for short men. Figure 3 shows the geographic distribution of the percentage of short men in each town, after adjustment for age and social class. The 12 towns to the west of Great Britain contain $21.8 \%$ short men compared with $18.2 \%$ in the 12 eastern towns $(p<0.001)$. When the same data are divided

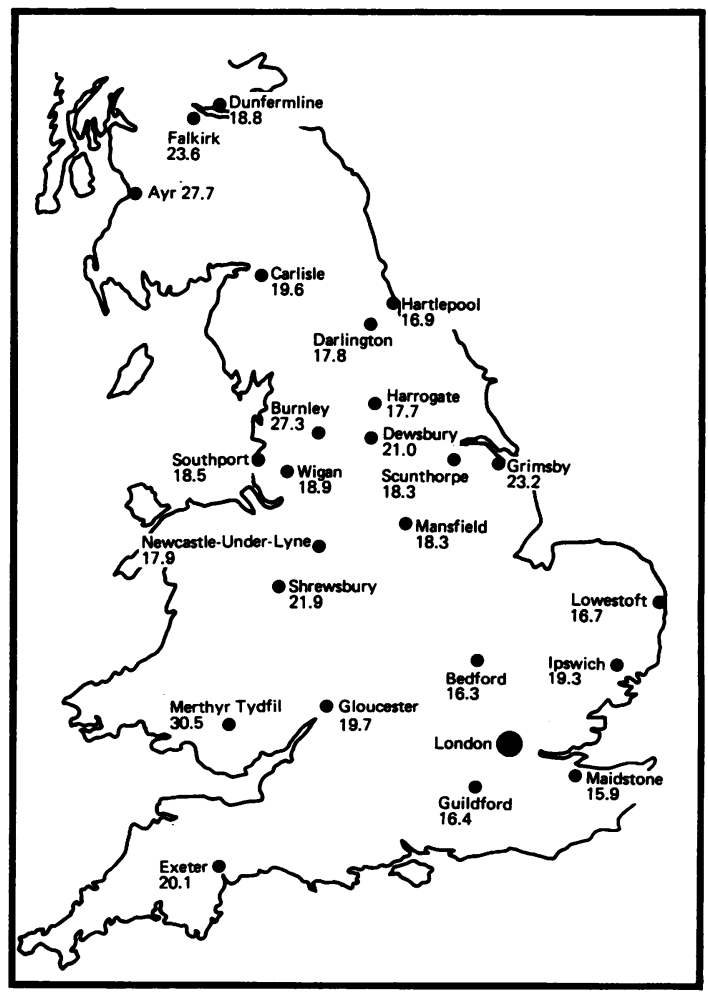

Fig 3 Geographic distribution of percentage of short men $(<167.9 \mathrm{~cm})$ adjusted for age and social class. 


\section{2}

horizontally the $20.7 \%$ of short men in the 12 northern towns is not significantly different from the $19 \cdot 2 \%$ in the south.

\section{BLOOD GROUPS}

There are some geographic variations in the distribution of the $\mathbf{A}, \mathbf{B}, \mathbf{A B}$, and $\mathrm{O}$ blood groups in Great Britain. ${ }^{8}$ The mean height of the men in each blood group was determined but as no significant difference was found between the groups the data were not explored further.

\section{Discussion}

Height is generally acknowledged to be a product of genetic and environmental factors, but the proportionate contribution of each influence remains uncertain. Our data demonstrate that there is a strong temporal trend towards increasing height in British men born between 1919 and 1939/1946. The initiatives and advances made in public health between 1906 and 1930 , the improved nutrition in infancy and childhood which contributed to the prevention of rickets, as well as the general improvement in economic prosperity across all social classes, are all reflected in the increased growth and development of children during this period. The levelling-off of growth in those born in the 1930s, despite the limited introduction of school milk in 1934 could be a result of the effects of the economic depression on that generation of children. Baker et al presented data on height of 8- and 9-year-old school children born between 1912 and 1932 (examined 1921-1941) in the Rhondda Valley, an area of considerable socio-economic deprivation between 1926 and 1939. ${ }^{9}$ The mean height increased steadily during the period 1921-1941 and the authors questioned whether height was a reasonable indicator of nutritional change. However, those children who were born between 1912 and 1926 would not have been subjected in their early years to the marked deprivations of the 1926-1939 period. The full effect of that period of deprivation is most clearly seen in those born in that period and would only become apparent when the heights of children or adults from that decade are available for comparison. There would appear to be no inconsistency between the Welsh data and ours as both show an increase in mean height for those born between 1912 and 1932 .

SOCIAL CLASS DIFFERENCES OVER TIME

In a recent review, "Nutritional monitoring of the health of the nation", Acheson uses height as a major index of nutritional status. ${ }^{10} \mathrm{He}$ contrasts data from Boyd Orr (1936) ${ }^{11}$ with those derived from the recent DHSS survey. ${ }^{4}$ Boyd Orr reported a remarkable mean difference in stature of $17.5 \mathrm{~cm}\left(7^{\prime \prime}\right)$ between
Mary Walker, A G Shaper, and Goya Wannamethee

approximately 50 13-year-old public school boys measured in 1935 and about 1200 13-year-old council school boys measured in 1932-4. Acheson contrasts this $17.5 \mathrm{~cm}$ difference with a $3.0 \mathrm{~cm}$ difference observed between men aged 16-64 years in social classes I and II compared with classes IV and V in 1980 (DHSS 1984) and concludes that "much of the difference in stature between social groups has disappeared". ${ }^{10}$ When the same DHSS data are examined by year of birth and social class, it is clear that the social class difference in height between non-manual and manual workers is at least as pronounced for those born in 1960 as for those born at any time in the preceding 40 years (figure 4 ). The flattening of the curves in the thirties is consistent with the British Regional Heart Study findings, and the convergence in height of the subjects born in 1941-5, during the years of rationing, is a particularly interesting feature. This group was also the first to benefit fully from the Education Act of 1944 which made the provision of milk and school meals statutory. The additional information on height from the 1946 birth cohort, for non-manual and manual workers, is consistent with the DHSS data (figure 4). In a Swedish study carried out in $1980-1$, a diminishing difference with time in mean height between the sons and daughters of unskilled (manual) workers and senior salaried (non-manual) employees was found for those aged 17-74. For 17-year-olds born in 1963 the difference in height between the two socio-economic groups, for both males and females, had almost disappeared. ${ }^{12}$

\section{POSSIBLE EXPLANATIONS}

The social class groups in the present study demonstrate a significant difference in mean height which, if causally related to socio-economic status, suggests that in Great Britain height did not reach its

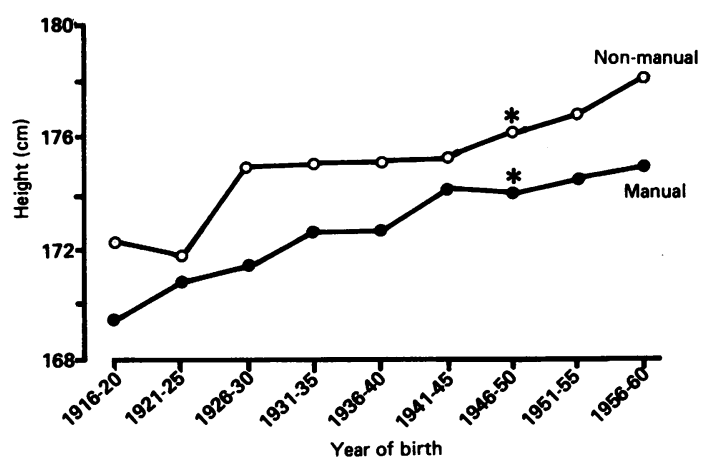

Fig 4 Mean height by five-year birth groups for non-manual and manual workers derived from DHSS data. ${ }^{*}=1946$ MRC Birth cohort. 
full potential in those born into the lower income groups in 1919-1939. This might be explained to some extent by poverty and poor nutrition in childhood. ${ }^{13}$ There is also evidence that women who smoke during pregnancy produce smaller babies than those who do not. ${ }^{14}$ Few women smoked before 1920 but the numbers increased from 1920 to 1950 , by which time $40 \%$ of women were smoking. ${ }^{15}$ Evidence from more recent studies indicates that smoking is strongly related to social class, with smoking rates remaining high in women in the manual working groups while a decrease has occurred in women in the non-manual classes. $^{16}$

\section{Social mobility}

It has been suggested that taller people selectively move up the social class scale. ${ }^{17}$ If this were true there would be a continual increase in the difference in height between the social classes. Power et al considered this issue using data from the 1958 National Child Development Study, in which height at age 23 was self-reported but not measured. ${ }^{18}$ They concluded that social mobility between birth and 23 years was selective with respect to height, but that mobility did not account for the social class gradients in height.

\section{Ageing and height}

A comparison of social class differences in height over time does not need to take into account a decrease in height with age, since both social class groups might be expected to experience a similar decrement. A study of the decline in height with age in two Welsh communities $^{19}$ indicated that any decrement which did occur was most marked over the age of 60 years, which is beyond the age range of this study.

\section{Geographical mobility}

The variation in height between the towns can be explained in part by age and social class, but a significant residual difference remains. Migrants into an area/town are known to make a small contribution to increasing the mean height of men in the town. ${ }^{40}$ Towns with economic prosperity are more likely to attract people into them, but the geographic variation in height, which is more marked on an east-west than a north-south basis, is likely to be due to both ethnic and economic influences.

\section{CONCLUSION}

Evidence exists that in those born in Great Britain up to 1960 , adult height has continued to increase with year of birth but that a significant difference in adult height between manual and non-manual workers persists undiminished. One implication of these observations is that year of birth and social class must both be taken into account in any analysis in which height is related to other measures of health or disease.
The British Regional Heart Study is a British Heart Foundation Research Group. It is also supported by the MRC, DHSS, The Chest, Heart and Stroke Association and The Scottish Hospital Endowments Research Trust. The MRC National Survey of Health and Development, Department of Community Medicine, University College London, kindly supplied data from the 1946 Birth Cohort.

\section{References}

${ }^{1}$ Rona RJ. Genetic and environmental factors in the control of growth in childhood. Br Med Bull 1981; 37: 265-72.

2 Rona RJ, Swan AV, Altman DG. Social factors and height of primary school children in England and Scotland. $J$ Epidemiol Community Health 1978; 32: 147-54.

${ }^{3}$ Goldstein H. Factors influencing the height of seven year old children - results from the National Child Development Study. Human Biol 1971; 43: 92-111.

${ }^{4} \mathrm{Knight}$ I. The heights and weights of adults in Great Britain. London: HMSO, 1984.

${ }^{5}$ Shaper AG, Pocock SJ, Walker M, Cohen NM, Wale CJ, Thomson AG. British Regional Heart Study: cardiovascular risk factors in middle-aged men in 24 towns. Br Med J 1981; 283: 179-86.

${ }^{6}$ Whitehouse RH, Tanner JM, Healy MJR. Diurnal variation in stature and sitting height in 12 to 14 year old boys. Ann Human Biol 1974; 1: 103-6.

${ }^{7}$ Braddon FEM, Rodgers B, Wadsworth MEJ, Davies JMC. Onset of obesity in a 36 year birth cohort. Br Med J 1986; 293: 299-303.

${ }^{8}$ Mourant AE, Kopec AC. The distribution of the human blood groups. Oxford: Oxford University Press, 1976.

${ }^{9}$ Baker IA, Cochrane AL, Elwood PC. Growth surveillance (letter). Int J Epidemiol 1977; 6: 293.

${ }^{10}$ Acheson D. Nutritional monitoring of the Health of the Nation. J Soc Health 1987; 6: 209-14.

11 Boyd Orr J. Food, health and income. London: Macmillan, 1936: $39-41$.

12 Nystrom Peck AM, Vagero D. Adult body height and childhood socio-economic group in the Swedish population. J Epidemiol Community Health 1987; 41: 333-7.

13 Yudkin J. The nutritional status of children and mothers of industrial towns. Med Officer 1944; 72: 93-102.

14 Butler NR, Goldstein H. Smoking in pregnancy and subsequent child development. Br Med J 1973; 4: 573-5.

15 Lee PN. Statistics of smoking in the United Kingdom. Tobacco Research Council Paper 1, 7th Edition. London: Tobacco Research Council, 1976.

${ }^{16}$ OPCS General Household Survey. Cigarette smoking 1972-1982. Government Statistical Service GHS 83/3, July 1983.

${ }_{17}^{17}$ Heath A. Social Mobility. Glasgow: Fontana Books, 1981.

18 Power C, Fogelman K, Fox AJ. Health and social mobility during the early years of life. $Q J$ Soc Affairs 1986; 2: 397-413.

${ }^{19}$ Miall WE, Ashcroft MT, Lovell HG, Moore F. A longitudinal study of the decline of adult height with age in two Welsh communities. Human Biol 1967; 39: 445-54.

${ }^{20}$ Martin WJ. The physique of young adult males. London: HMSO, 1949. 